\title{
INTERACTIVE MOBILITIES: CONCEPTUALISING VFR TOURISM OF INTERNATIONAL STUDENTS
}

My N. D. Tran (Corresponding author) $\mathrm{PhD}$ Candidate

Faculty of Environment, Society and Design Lincoln University, New Zealand

Address: 30a Rothsay Road, Ngaio

Wellington, New Zealand, 6035

\section{Kevin Moore}

Associate Professor in Psychology and Tourism

Faculty of Environment, Society and Design

Lincoln University, New Zealand

\section{Michael C. Shone}

Senior Lecturer in International Tourism and Hospitality Management

Department of Hospitality and Service Industries

Ara Institute of Canterbury, New Zealand 


\title{
INTERACTIVE MOBILITIES: CONCEPTUALISING VFR TOURISM OF INTERNATIONAL STUDENTS
}

\begin{abstract}
The relationship between tourism and migration that has resulted from increasing global mobility is a complex phenomenon. As part of that phenomenon, research has shown a strong connection between international education, particularly at the tertiary level, and tourism. In particular, international students have been found to have a strong impact on the tourism industry of their study country. This paper investigates a specific form of tourism in which international students are involved: Visiting Friends and Relatives (VFR) tourism. It details an initial conceptual understanding of the relationship between international students and VFR tourism. A conceptual framework is developed to help illustrate this relationship, highlight new avenues for research, and indicate how this relationship connects with the wider tourism-migration literature. The framework suggests that the interface between VFR tourism and international students can be explained through a number of aspects, two of which are addressed in the paper: VFR travel behaviour and host-guest dynamics in VFR tourism of international students. These aspects are analysed throughout the pre-, during, and post study periods. The paper sheds further light on emerging VFR related concepts - such as VFR tourism in a third place - as well as theories regarding the notion of hosts and guests in the modern mobile world. Suggestions for future research are also provided.
\end{abstract}

Keywords: international students, VFR tourism, host-guest relationship, mobility

\section{Introduction}

Global mobility has provided opportunities for many industries to develop and grow. It is depicted through movements of populations (e.g., tourists, residents, second-home owners and recreationalists), objects (e.g., capital, resources) and ideas (e.g., information, expertise) across boundaries (Dredge \& Jamal, 2013; Shone, Simmons, \& Dalziel, 2016). Among consequential phenomena of worldwide mobility are international education (also known as 'export education') and tourism. It is increasingly common for people to travel overseas for the purpose of education, especially those who are from developing countries seeking to obtain high quality university degrees in developed countries. On a global scale, it has been estimated that around 4.3 million tertiary students are being educated outside their home country, and this number could double by 2025 (Tourism Industry Association New Zealand, 2013). With such rapid growth projected, the theme of student mobility has become a focus for many researchers.

The importance of international students as a tourism market has been noted in the literature (Glover, 2011; Ryan \& Zhang, 2007). Visiting friends and relatives (VFR) is one of the forms of tourism in which international students participate. Although the broad suite of benefits associated with VFR tourism are increasingly recognised by researchers and industry managers, this type of tourism has not been studied to its full potential (Backer, 2012). Research that has focused on the VFR tourism aspect of international students' behaviour often emphasises their role as hosts for visits by family members and friends (Liu \& Ryan, 2011; Shanka \& Taylor, 2003), as well as their economic contribution to destination areas (Taylor, Shanka \& Pope, 2004; Weaver, 2003). However, their potential role as VFR guests and the duality that such a conceptualisation presents, appears to have received comparatively sparse attention within this research area. 
The argument of this paper is that the intersection between international students and VFR tourism is a dynamic and complex - yet under-researched - area of tourism mobilities. The paper seeks to offer a conceptual discussion of this intersection, which would add to the understanding of the migration-tourism nexus in general. For clarity, it should be emphasised that its focus is on the relationship between two distinctive phenomena: VFR tourism, and international education. It is not concerned with educational tourism as a specific type of tourism.

The paper first provides some context for understanding the conceptual model. It does this by, first, reviewing literature on the concept of VFR tourism and the host-guest relationship within this form of tourism. The proposed conceptual framework is then presented and discussed in detail. That discussion considers the VFR experience of international students according to the pre-, during and post- education periods. Finally, the paper concludes with a summary of its theoretical contribution and avenues for further research.

\section{VFR tourism}

\subsection{The concept of VFR tourism}

Migration contributes to the expansion of individual social networks both domestically and internationally. This has helped facilitate a particular form of tourism, namely VFR. According to Janta, Cohen and Williams (2015), VFR tourism can be conceptualised socially as a leisure constituent of VFR mobility. It is argued that, after migrating, migrants might decide to take subsequent trips to their former place of residence to visit friends and/or relatives because, as former permanent residents, they would likely have established significant social ties there (Williams \& Hall, 2002). Migrants themselves also become a pull factor that motivates visits by friends and relatives from their former place of residence. As such, migration is an important contributing factor to VFR tourism leading to the progressive growth of the tourism-migration relationship (Dwyer, Seetaram, Forsyth \& King, 2014).

Backer (2007) described VFR travel as a form of travel whereby either (or both) the purpose of the trip or the type of accommodation involves visiting friends and/or relatives. Larsen, Urry and Axhausen (2007) posited that 'VFR tourism' is about being co-present with 'significant faces', being their guests, receiving their hospitality and, perhaps, enjoying their knowledge of local culture. Such an approach raises the following questions: How are 'significant faces' to be defined? That is, how close must a friend (or relative) be in order to be considered a "significant face"? At the margins, for example, some travel involves social 'contacts', perhaps made via a social network of friends and relatives but not known directly by the tourist. The definition of VFR tourism by Larsen et al. (2007) also emphasises the guests' perspective and thus may not cover all situations where VFR tourism occurs. More recently, Munoz, Griffin and Humbracht (2017) suggested that VFR can be defined as a form of mobility influenced by a host that involves a face-to-face interaction between host and visitor within the destination. Their definition takes into account the limitations of previous definitions and appears to be inclusive of most situations where VFR occurs.

It is worth noting at the outset, that, in the VFR tourism literature, the term 'VFR travel' is often used interchangeably with 'VFR tourism'. According to Yousuf and Backer (2015), although the term 'VFR tourism' has been traditionally used more frequently, 'VFR travel' is increasingly gaining popularity in useage. VFR travellers are also characterised differently from tourists for the distinction in their primary purpose of travel, accommodation, and engagement in touristic activities (Backer \& Morrison, 2015). While the difference and the complexity in distinguishing these two terms are acknowledged, the term 'VFR tourism' is employed throughout the paper for consistency. This is partly because the paper focuses not only on the travel element of the concept, but also more broadly on the socio-cultural aspects and the host-guest relationship within the phenomenon and, to that extent, overlaps with analyses of the tourist experience. It is also used because, for international students, travelling to visit friends and relatives is partly a way of seeing more of the destination where the 
friends/relatives reside, and therefore, what might be referred to purely as 'VFR travel' by others could still be a touristic behaviour to international students.

Relatedly, debate surrounds the issue of whether or not VFR should be considered a tourism segment or simply a tourist activity (Moscardo, Pearce, Morrison, Green \& O'Leary, 2000). Seaton (1994) considered it as part of a hybridised form of tourism in which numerous activities and motivations are at work throughout one trip. However, the characteristic dual role of VFR tourism, both as a motivating factor and a tourism activity, makes it unique and a highly relevant tourism category while, nevertheless, a confusing one (Asiedu, 2008). It is also important to acknowledge that the VFR market is not one homogenous group. Efforts

have been made in examining the heterogeneity of the VFR market, and previous literature has suggested different ways to categorise the market such as by travel distance (Moscardo et al., 2000), trip patterns (Hu \& Morrison), and trip expenditure (Lee, Morrison, Lehto, Webb \& Raid, 2005). Seaton and Tagg (1995) also disaggregated the VFR market into three categories based on the visited parties: visiting friends (VF); visiting relatives (VR); and, visiting both. A clear understanding of the distinctiveness between these groups, especially between the VF and the VR, remains unrealised (Yousuf \& Backer, 2017; Seaton \& Tie, 2015). More research is needed to understand the travel behaviour of particular VFR groups, as well as the differences among them.

It was mentioned earlier that migration is a contributing factor to VFR tourism. Accordingly, immigrants are often noted has having a high participation in VFR tourism. Many sub-groups of immigrants with specific VFR travel behaviour have been looked at such as retiree immigrants (A. Casado-Díaz, Casado-Díaz, \& Casado-Díaz, 2013), expatriates (Dutt \& Ninov, 2017), and members of various diaspora (Duval, 2003). International students, as a category, has been recognised as a growing and important VFR market (Liu \& Ryan, 2011; Seaton \& Tie, 2015; Taylor et al., 2004). This particular group of immigrants possesses distinguishing characteristics compared to others including initial fixed timeframe in the immigrating country (usually based on the study courses), being in the younger age groups and, consequently, being in the earlier stages of a life cycle. Such traits may influence their VFR travel behaviour and distinguish it from other groups of immigrants.

\subsection{Hosts and guests in VFR tourism}

The tourism literature often conceptualises guests as tourists who undertake a journey to, and stay in, various destinations that are distant from their normal place of residence, and who take on different roles and activities from the resident population of the destination (Ross, 1994). The definition of hosts has been less noted because, historically, tourism studies have focused on tourists (Cohen, 1995). In a conventional sense, hosts appear to be taken as the assumed counter in the binary host-guest relationship. Sherlock (2001) made an effort to clarify hosts by introducing the term "local" which means to be connected to residency, with its connotations of belonging and commitment to the place ('locale') and the community. These distinguish them from tourists. As a result, in the tourism context, guests are seen as engaging in consumption practices and hosts as engaging in productive practices (Sherlock, 2001).

In the post-modern world where global movements are increasingly common, such conventional understandings of hosts and guests as local people and out-of-town visitors is arguably less useful. According to Sherlock (2001), the blurred distinction between them is due to the complex phenomenon of migration. She suggests that the transient nature of the world population adds to the complication in separating hosts from guests. For example, there are circumstances where hosts become guests in their local area (Duval, 2003), and vice versa (Liu \& Ryan, 2011). As a further example, in 'third places' one person may arrive earlier than another and, to some extent, start to act as a host when the latter arrives. Hence, in order to better identify hosts and guests in the tourism context, both spatial and behavioural aspects should be taken into account.

In the VFR tourism context, guests (or VFR travellers) are those who either reported visiting 
friends and relatives as the main purpose of their trip, and/or who stay with their friends and relatives during their trip (Backer, 2012, p.75). Although type of accommodation is a defining factor for VFR tourism, it is not so for VFR guests. VFR hosts are defined as someone who has friends and/or relatives visit and stayed at least one night in their destination (Yousuf \& Backer, 2017). They normally provide various hospitality services to their guests including accommodation, food and travel guidance. In addition to definitional issues, classification is important because it serves as a foundation for conceptual and empirical advancement in related research (Bailey, 1994). Thus, different typologies of VFR hosts and guests have been developed to help better understand their roles and behaviours. Classifications of VFR guests and VFR hosts are often based on their main purpose of visit, choice of accommodation, by their guesting/hosting behaviour (Backer, 2012; Shani \& Uriely 2012; Yousuf \& Backer, 2017).

The host-guest relationship in tourism destinations could potentially be resentful and hostile due to differences in terms of economic, social and cultural between hosts and guests (Smith, 1989; Oppermann, 1993). With VFR tourism, these problems are likely to be ameliorated to some degree because most VFR participants would have an extant level of familiarity with the socio-cultural and other settings that prevail in the communities they visit and, unlike other tourists, they do not visit primarily for recreation but rather to fulfill some socio-cultural obligations (Asiedu, 2008). VFR visitors are likely to have some prior social and/or experiential connection to the place, whether it is having friends and/or relatives there, or even originally being born there. However, the extent of such familiarity differs from case to case.

Taken together, the host-guest relationship in VFR tourism is rather complex. First, VFR hosts and VFR guests have an effect on each other in terms of travel decision making and total trip experience satisfaction (Larsen et al., 2007; Shani \& Uriely, 2012). The second matter is the duality of the host and guest roles. Relevant literature focuses mostly on either VFR hosts (Bischoff \& Koenig-Lewis, 2007) or VFR guests (Lehto, Morrison \& Uriely, 2001; Moscardo et al., 2000) independently, rather than the dynamic interaction of both together and the possibility that individual people may alternate between hosting and guesting roles with friends and family. The third issue is the host-guest interaction in VFR tourism. In VFR tourism, where guests are more likely to have some socio-cultural similarities and stay in the same place with hosts, more host-guest interaction is enabled compared to other types of tourism. Yet the socio-psychological experience of hosting and guesting in such VFR tourism is nuanced. Family members, for example, may have responsibilities and obligations (e.g., parents feeling responsibility to look after their children, irrespective of location) that cut across the host-guest roles. The relationships between hosts and guests in VFR tourism, and the associated experiences of these relationships, are unclear which suggests a need for further empirical research and theoretical understanding.

\section{International students and VFR tourism}

\subsection{The conceptual framework}

The proposed conceptual framework in Figure 1 aims to provide a structured view of the relationship between, and key dimensions of, VFR tourism and international students. Whilst showing how this connection is positioned in the wider tourism-migration nexus and in connection with other patterns of global mobilities, it also incorporates various aspects of the dynamics and complexity of the connection.

Figure 1: A conceptual framework of the relationship between international students and VFR tourism

[Insert Figure 1] 
Tourism and migration could be considered as interrelated outcomes of increasing mobility. More specifically, increased global mobility appears to have triggered the development and growth of international education that comprises part of the overall 'migration complex'. In many cases, international education, as a temporary immigration phenomenon, could be the starting point for future long-term migration. Within this international education sub-sector, international students are the key component. As already established above, a particular type of tourism that has a strong connection with migration is VFR tourism. The framework proposes that international students and VFR tourism interconnect in a complex manner. This framework attempts to start unfolding this complexity through two main dimensions: overall patterns of VFR travel behaviour (the 'spatial' and 'behavioural' aspects), and the 'hosting' and 'guesting' roles of international students (the 'socio-cultural' aspect). These elements are discussed in chronological sequence aligning with the students' experience of international education: before university studies, during university studies, and after university studies have been completed (the 'temporal' aspect). While acknowledging that VFR travel behaviour may comprise various sub-elements, the framework highlights two key flows of VFR tourism (international and domestic) and the types of 'being' involved in VFR tourism (visiting/being visited/meeting in a third place). The conceptual framework also suggests that these elements, in turn, impact upon both the tourism sector and international education sector (the indicated feedback arrows in Figure 1). While much of the literature focuses on the economic aspect of this form of VFR tourism, the focus of this paper, and the framework, is primarily on its socio-cultural significance. Further explanation and elaboration of elements in the framework is provided in the following sections.

\subsection{Pre-education}

The relationship between international students and tourism has been examined extensively within the literature. As an example, international students' choices of educational destinations can be influenced by their tourism related perceptions (Wang \& Davison, 2008, Glover, 2011). More specifically, reasons for selecting a particular country in which to study abroad are closely related to the available tourism offerings and/or opportunities to undertake tourist activities in the country (Llewellyn-Smith \& McCabe, 2008). As a result, such international students are likely to travel for tourism purposes during their study period and this resultant travel behaviour has been explored in the literature (Gardiner, King \& Wilkins, 2013; Glover, 2011; Weaver, 2003).

The period before international students commence their programme of study in the host country, however, has received little attention from researchers. Limited emphasis has been placed on personal links such as having visited the host country before, having family or friends who have previously studied or are studying there, and having friends or relatives who live there (Glover, 2011). On this point, Collins (2008) suggests that having family or friends in the host country could be a form of security and, consequently, influence students' choice of studying destination. In other words, they may choose their study destination on the basis of the presence of friends and family members in the area. If this was the case, friends and relatives of potential international students could be one pull factor that encourages them to undertake VFR trips.

The VFR travel behaviour of international students during the pre-education period is likely to be similar to any other VFR travel behaviour. Importantly, episodes of VFR travel during this phase are, almost by definition, likely to be international in form (rather than both international and domestic, as in the next chronological stage.) There is also an emerging pattern of VFR when friends or family members travel to a third place to meet each other. With increasing global mobilities VFR in a third place is, arguably, likely to grow. This form can happen across all three examined periods of the students' education. It is introduced here in the pre-education period, and more details are discussed in section 4 of this paper.

In terms of spending, although researchers and industry managers have in the past largely neglected the economic contribution of VFR tourism because of the assumption that VFR 
travellers use free accommodation provided by their friends and relatives, other studies have shown the opposite (e.g., Griffin, 2016; Griffin, 2013; Moscardo et al., 2000). Lee et al. (2005) also suggested that while VFR travellers might spend less on commercial accommodation, they appear to spend more on shopping, meals and other activities. Such outcomes might be more relevant to the case of international students, whose financial capability can often be limited compared to other working groups, but who nevertheless have a high tendency to engage in entertainment and leisure activities with friends/relatives. These suggest that the potential economic contribution of international students to the tourism industry, even before they start their education at the destination, may be substantial. More broadly, VFR tourism and international education form a partial interdependency. This reciprocally reinforcing relationship is represented in the framework by the arrows that cycle between VFR tourism and international education. That is, as well as generating VFR tourism, international education is itself generated in-part by VFR tourism, especially in the 'pre-education' phase of the framework.

Socio-culturally, with VFR travel during the pre-education period, potential international students play the role of VFR guests. In this sense, it begins a process of socio-cultural adaptation to the future study country. Crucially, prior experience of being a guest might influence their experiences and practices of being VFR hosts and guests later during their international education at the destination. For instance, they are likely to be more understanding of what their VFR guests' needs are because of their previous experience of that role. In addition, having travelled to visit friends and relatives in a potential destination for overseas studies provides the students with the opportunity to experience the local culture and living environment. This then could be a determining factor that leads, ultimately, to their decision to undertake university study in this host country. That is to say, it is possible that such travels may have a causal relationship with the choice of study destination through a mix of familiarity and curiosity. However, more research is needed to verify these socio-cultural links.

\subsection{During education}

According to Dwyer et al. (2014), when immigrants depart from their home country to establish new lives in another country, tourism may be stimulated through visits by friends and relatives (VFR) in both directions. As such, they represent a cohort with great potential for engagement in VFR tourism, both inbound and outbound. The same analysis can be applied to international students. Much of the academic literature has explored the contribution of international students to VFR tourism during their study period by being VFR visitors themselves, and by attracting visits from their friends and relatives (Ryan \& Zhang, 2007; Weaver, 2003). Having friends and relatives visit and acting as local hosts can also encourage the students to undertake more tourist activities than they would normally, which in turn, results in substantial expenditures (Shani \& Uriely, 2012).

One key point that makes the 'during education' period different from other periods is that international students can be either VFR guests or hosts, or even both. In addition, this dual host-guest possibility can occur within the study country and within the origin country (when a student returns 'home' for a visit). They are VFR guests when they travel to visit their friends and relatives, and conversely, they are VFR hosts when they receive visits from their friends and relatives. When international students are visited by their friends and relatives, they are VFR hosts. If they then travel to other places or participate in tourism activities together, they could be considered as guests in the study destination. This is when the role of being hosts and guests blurs in VFR tourism, and such blurring of role boundaries is particularly evident in the case of international university students. It is arguable that their VFR travel behaviour might also differ depending on what role they play, and perhaps even when - during their study stay - they embody these differing roles, within this host-guest duality. 
As a result of having opportunities to be both VFR hosts and VFR guests, the socio-cultural influence of VFR tourism on international students is likely to be significant during their period of study. Larsen et al. (2007) argued that physical, co-present interaction is fundamental to social interaction within institutions, families and friendships, for producing trust, sustaining intimacy and pleasurable gatherings. Accordingly, VFR tourism in this period contributes to the development and enhancement of social networks while studying, which in turn, would enrich the students' social well-being, given the centrality of social connectedness to subjective experiences of well-being (e.g., Lamblin, Murawski, Whittle \& Fornito, 2017). Furthermore, similar to other types of tourism, VFR tourism creates a platform for visitors and hosts to interact and exchange cultural values. An example could be international students who might have gained experience of the culture of the country where they had gone to study and, subsequently, convey that cultural understanding to friends and family members during their return visits. Cultural exchange also occurs when friends and relatives visit the students and get to know about the local culture through their trips.

A further factor that has an impact on VFR tourism of international students during their education at the destination is length of educational stay. That is, it likely varies depending on the students' education type. For instance, in the case of a student who only stays for six months during an academic exchange programme, the chances of receiving visits from friends and relatives might be lower than someone who comes for a full university degree of several years. This could be because VFR tourism highly depends on personal relationships and connections that usually take time to establish. Conversely, it could also be argued that shorter length of stay might create an urgency among the students and their friends/relatives to make the visits, which results in a high rate of visits within such period of time (i.e., a relatively high rate of VFR). Shorter time in the destination might also limit their ability to learn and familiarise themselves with the local culture. Consequently, this limitation could affect their hosting behaviour or their willingness or ability to meaningfully act as hosts at all.

Another important social aspect is the impact of VFR tourism on students' wellbeing during their study (as noted above). Literature has shown that international students experience several challenges during the course of their study such as homesickness, acculturative stress (cultural shock), language barriers, and lack of a robust social network (Götz, Stieger, \& Reips, 2018; Marriott et al., 2010). Visits to friends and relatives are proved to have a significant impact on the students' emotional wellbing (Mason, 2004). Moreover, visiting friends and relatives 'back home' is an opportunity for the students to form a cultural reconnection with the past, which is suggested to assist them with adaptation in the host country by providing them a buffer from the upheavals associated with migration (King \& Dywer, 2015, p.54).

One significant social consequence is that VFR tourism enables its participants to 'feel at home' while being away from their own homes. This effect may be particularly important for internatonal students whose homesickness is often a recognised challenge (Götz et al., 2018). It is argued that VFR tourism enhables its participants to feel at home while being away from their own house (Shani, 2013). Accordingly, experiences of international students in VFR tourism might influence their feeling of being at home while studying in the host country and, perhaps, contribute to the solution for their homesickness issue. However, Shani (2013) also revealed the possibility that VFR tourists may experience a sense of being 'away', particularly when the meaning of 'home' is examined in terms of privacy and situational control, as well as sociability in associations. He argued that VFR tourists' feelings of privacy at friends' and relatives' homes is often weaker than in a paid hotel, and by being noncommercial guests they are also dependent on the hosts' schedule and under certain social obligations that undermine their ability to achieve situational control. Hence, the feeling at home resulted by the students' VFR tourism experience is still debateable and might vary depending on their roles as either VFR hosts or VFR guests, and the form of accommodation. In general, VFR during the studying period of international students has diverse and nuanced impacts on their overall overseas study experiences. 


\subsection{Post education}

After completing their academic programmes, international students are also a promising source of return/repeat visits to the country of study (Gardiner et al., 2013). In an Australian context, for example, once graduated and returned to their home countries, the graduates' propensity to visit Australia is high, particularly coming back for holidays or for visiting friends and relatives (Shanka \& Taylor, 2003). As a result, the economic contribution of international students to VFR (and other) tourism may continue after their study completion. VFR travel in this period might be less compared to the 'during education' period due to other commitments such as jobs and family. Also, they are likely to play the 'guest' role most often. The difference is that they would have more knowledge about the destination and the local culture. Such insights obtained through the period of living in the place for their education might influence their travel behaviour. For instance, less effort might be required to arrange subsequent trips with their friends and relatives. Also, targeted places for these subsequent trips could be where the students themselves have not travelled to during their study. Accordingly, return VFR trips to studying destinations are likely to be combined with tourism purposes.

In terms of socio-cultural impacts from these return visits, VFR tourism after study completion helps international students maintain the relationship (kinships, friendships, and/or attachment to place) they have at the destination, some of which were established during their study. Framed within this view of VFR tourism as a form of global mobilities, Duval (2003) suggested that diasporic return visits, as a form of VFR tourism, serve as a means towards maintaining social and cultural ties with family members and friends in their home country. With international students, it is not about the social ties in their home country, but rather, a place that contains memories and relationships as part of their life journey. These return visits to familiar places (in the case of international students is the studying destination), by recalling personal links and memories, can also help enrich one's emotional wellbeing and results in better personal functioning and control (Pearce, 2012). This point definitely raises an important potential benefit of return VFR visits, perhaps more so for international students who experience reverse cultural shock when returning home following their study. That is, return visits 're-validate' experiences that might distinguish them from their social networks in their 'home' country and provide them with a sense of life-continuity and integration.

Another notable aspect of VFR tourism after study completion is its relationship with decisions concerning long-term migration. VFR tourism has been shown to have strong links with community settlement processes, migration trends and family attachments (King \& Dywer, 2015). The combination of tourism and education experiences can make a place particularly appealing in the international students' eyes. Therefore, return visits in the posteducation phase might encourage students' decisions regarding future migration, unrelated to further educational opportunities.

\section{VFR tourism in a 'third place'}

The proposed conceptual framework explicitly incorporates an emerging pattern of VFR travel: VFR in a 'third place' (i.e., a 'neutral' geographic location which is 'home' for none of the VFR travel parties). There are instances when friends or family members travel to a third place to meet each other, wherein none of them have formal hosting responsibilities. As VFR mobilities take on increasingly diverse spatial forms, visits to third places for holidays to meet family and/or friends can complement or supplant those between the homes/home areas of the participants (Janta et al., 2014). According to Backer (2012), two key components of defining VFR include 'purpose' and 'accommodation'. Munoz et al. (2016) have extended this definition to conceptualise VFR tourism as a form of mobility influenced by hosts that involves a face-to-face interaction between hosts and visitors (guests) in the destination. This paper argues that VFR in a third place satisfies the elements of travelling for VFR purpose and having host-guest interactions and, thus, can be considered a form of VFR tourism. It 
expands the conceptualisation of the VFR phenomenon and is a demonstration of its evolving dynamism.

The host-guest relationship manifested in VFR in a third place is likely to be distinctive because all participants have a neutral role towards the visited place. According to Griffin (2016), VFR experiences are often discursively considered within the physical home and local community of the host, and the host's routine and quotidian life is never far away; but when host and guest visit a new region, the context shifts to a leisure vacation for all involved. In fact, it may also be a cheaper - and therefore a greater frequency - way for all involved by allowing shorter-haul travel for each party and thus allowing them to 'meet halfway'. Griffin (2016) also suggested that intra-regional travel can provide VFR hosts and guests with new identities, perceptions, behaviours and relationships out of the ordinary tourism contexts that are less available in the home of the resident. That is, friends and relatives will provide quite different experiences when being visited in their home areas versus in 'neutral' destinations. In addition, regional experiences, or subsequent trips, create a multi-destination trip that not only provides opportunity to spend time with friends and family but also satisfies desires for variety in travel (Lue, Crompton, \& Fesenmaier, 1993). Such trips are also likely to result in a dynamic interplay of host-guest roles within the VFR travel group and across the various dimensions of the VFR travel experience (e.g., at different times and at different locations/settings).

Patterns of VFR tourism in a third place are varied. They could be domestic, international or a combination of both. They are likely to be favoured by international students who wish to explore and travel as much as possible during their overseas study period. That is, VFR travel might be 'leveraged' by international students to allow greater experience of travel, either in the study country or other destinations with the advantage of being with familiar travel companions. A student studying in Auckland (New Zealand) may travel to Queenstown (New Zealand) to meet with his or her family who travel from their home country would be an example of VFR in a third place that involves both domestic and international travel by participants. Moreover, due to travellers' unfamiliarity with the place and non-hosting responsibility, VFR in a third place may not follow the same 'rules' as conventional VFR tourism. For example, the assumption that VFR travellers do not contribute economically to the accommodation sector would not be applicable. Also, as Griffin (2016) pointed out, the context of VFR tourism in a third place make those involved feel more as if they are on a leisure trip. As a result, they are likely to participate in more tourist activities.

With the dynamics of globalisation and increasing travel mobility, VFR in a third place is likely to grow. The conceptual framework explicitly incorporates this form of VFR tourism in the broader picture of the tourism-migration nexus. That is, while it may have particular significance for understanding international students' VFR tourism, it is also relevant for other migration-related forms of mobility. For international students specifically, such 'third place VFR tourism may serve to increase their broader acquaintance with the study country, provide a 'break' from the immediate study environment and alleviate any pressures associated with directly hosting friends or relatives in their home (which may often be relatively temporary and minimal forms of accommodation unsuitable for hosting). Furthermore, this form of VFR not only indicates an important avenue for future investigation of VFR tourism, but also embodies a new direction for the active development of VFR tourism and marketing.

\section{Conclusion}

The above discussion has emphasised the strength and complexity of the connection between international students and VFR tourism, and has proposed a conceptual framework to illustrate these links. All elements presented in the framework are interconnected and influence each other. The relationship persists over time (potentially a lifetime) with students engaging in VFR tourism as either hosts, guests, or both throughout the pre-, during and post education periods. Whereas much of the literature addresses the economic connection 
between international students and VFR tourism, this paper has emphasised consideration of the social and cultural aspects of this intersection. By focusing on VFR tourism of international students, the discussion identified a set of - often subtle and diverse relationships that, to date, has not been acknowledged in an integrated manner in theoretical and conceptual accounts of VFR tourism.

Perhaps of greatest importance, the paper provides an initial conceptualisation of the convergence between two increasingly significant global phenomena (i.e., international education and tourism) and identifies the VFR tourism-international university student nexus as an emerging area for further studies within and, to some extent, at the blurring margins of, tourism and migration. An indirect consequence of this conceptualisation is that it implies that tourism has evolved and become embedded within numerous aspects of global life and mobilities, not just international education. The proposed framework, by incorporating interactions between tourism and international education, invites its extension to understand how other global mobilities might interact with tourism. For instance, if the experience of VFR tourism and international education results in later migration, this then may link tourism to other global social and political issues such as housing supply and affordability, local community perceptions of global issues, and even responses to international refugee and financial crises. Countries which have high rates of participation in international education may, through tourism-related activity, also become more intricately involved with other global processes. This interesting position of the VFR tourism-international student nexus makes it a particularly worthy focus of study as part of that broader convergence.

Several gaps in the literature that might hinder the full understanding of the phenomenon were identified in this paper. We suggest that future research should explore these gaps, or investigate the links presented in the framework and other aspects of the phenomenon that may not have been identified here. Potential topics of interest for future research include the extent to which 'cultural distance' might affect the various aspects of international students' VFR travel, or VFR travel they stimulate (including cultural distance between students and study countries as well as between students and friends); longitudinal studies of the effect and the extent of VFR travel on post-education attitudes to the destination country; cross-cultural interactions involving VFR travel by international students of different nationalities; and, relationships between VFR experiences and permanent residency in host countries. In addition, one of the more far-reaching contributions that the conceptual framework could make is in considering and researching the various forms of hosting (and guesting) presented in VFR tourism generally. Hosts, for example, can be more or less familiar with a destination's culture, activities and social practices depending on their length of residence in the destination and the extent and kind of social networks they have developed within the destination. How these, and other, variables might affect the form of hosting and consequent tourism activity presents many opportunities for further research. 


\section{References}

Asiedu, A.B. (2008). Participants' characteristics and economic benefits of visiting friends and relatives (VFR) tourism - An international survey of the literature with implications for Ghana. International Journal of Tourism Research, 10, 609-621.

A. Casado-Díaz, M., Casado-Díaz, Ana B., \& Casado-Díaz, J. M. (2013). Linking tourism, retirement migration and social capital. Tourism Geographies 16(1), 124-140.

Backer, E. (2007). VFR travel an examination of the expenditures of VFR travellers and their hosts. Current Issues in Tourism, 10(4), 366-377.

Backer, E. (2012). VFR travel: It is underestimated? Tourism Management, 33, 74-79.

Backer, E. \& King, B. (2015). VFR travel research: International Perspectives. Bristol: Channel View Publicaions.

Backer, E. \& Morrison, A. The value and contributions of VFR to destinations and destination marketing. In E., Backer \& B., King (Eds.), VFR travel research: International perspectives (pp.13-27). Bristol: Channel View Publicaions.

Bailey, K.D. (1994). Typologies and taxonomies. Thousand Oaks, CA: SAGE Publications.

Bischoff, E. E. \& Koenig-Lewis, N. (2007). VFR Tourism: The importance of university students as hosts. International Journal of Tourism Research, 9, 465-484.

Cohen, E. (1995). Contemporary Tourism - Trends and Challenges, in R. Butler and D. Pearce (Eds), Change in Tourism: People, Places, Processes (pp. 12-29). London: Routledge.

Collins, F.L. (2008). Bridges to learning: international student mobilities, education agencies and interpersonal network. Global Networks, 8(4), 398-417.

Dredge, D. \& Jamal, T. (2013). Mobilities on the Gold Coast, Australia: implications for destination governance and sustainability. Journal of Sustainable Tourism, 21(4), 557579 .

Duval, D.T. (2003). When hosts become guests: return visits and diasporic identities in a Commonwealth Eastern Carribean Community. Current Issues in Tourism, 6(4), 267308.

Dutt, C.S. \& Ninov, I. (2017). Expatriates' learning: The role of VFR tourism. Journal of Hospitality and Tourism Management, 31, 253-264.

Dwyer, L., Seetaram, N., Forsyth, P. \& King, B. (2014). Is the migration-tourism relationship only about VFR? Annals of Tourism Research, 46, 130-143.

Eusébio, C.A. \& Carneiro, M.J.A. (2012). Determinants of tourist-host interactions: An analysis of the university student market. Journal of Quality Assurance in Hospitality \& Tourism, 13(2), 123-151.

Gardiner, S., King, B. \& Wilkins, H. (2013). The travel behaviour of international students: Nationality based constraints and opportunities. Journal of Vacation Marketing, 19(4), 287-299.

Glover, P. (2011). International students: Linking education and travel. Journal of Travel and Tourism Marketing, 28(2), 180-195.

Götz, F. M., Stieger, S. \& Reips, U. (2018). The emergence and volatility of homesickness in exchange students abroad: A smartphone-based longitudinal study. Environment and Behaviour, 1-28. Retrieved from: https://doiorg.ezproxy.lincoln.ac.nz/10.1177/0013916518754610

Griffin, T. (2013). Research note: A content analysis of articles on visiting friends and relatives tourism, 1990-2010. Journal of Hospitality Marketing \& Management, 22, 
781-802.

Griffin, T. (2016). Immigrant hosts and intra-regional travel. Tourism Geographies, 01 April, $1-19$.

Hsu, C.H.C. \& Sung, S. (1997). Travel behaviour of international students at a midwestern university. Journal of Travel Research, 36(1), 59-65.

Hu, B. \& Morrison, A.M. (2002). Tripography: Can destination use patterns enhance understanding of the VFR market? Journal of Vacation Marketing, 8(3), 201-220.

Janta, H., Cohen, S.A. \& Williams, A.M. (2015). Rethinking visiting friends and relatives mobilities. Population, Space and Place, 21, 585-598.

King, B. \& Dywer, L. (2015). The VFR and migration nexus - The impacts of migration on inbound and outbound Australian VFR travel. In E., Backer \& B., King (Eds.), VFR travel research: International perspectives (pp.46-58). Bristol: Channel View Publicaions.

Lamblin, M., Murawski, C., Whittle, S. \& Fornito, A. (2017). Social connectedness, mental health and the adolescent brain. Neuroscience and Biobehavioral Reviews, 80, 57-68.

Larsen, J., Urry, J. \& Axhausen, K.W. (2007). Network and Tourism: Mobile social life. Annals of Tourism Research, 34(1), 244-262.

Lee, G., Morrison, A.A., Lehto, X.Y., Webb, J. \& Raid, J. (2005). VFR: Is it really marginal? A financial consideration of French overseas travellers. Journal of Vacation Marketing 11(4), 340-356.

Lehto, X.Y., Morrison, A.M. \& O’Leary, J.T. (2001). Does the visiting friends and relative typology make a difference? A study of the international VFR market to the United States. Journal of Travel Research, 40(2), 201-212.

Liu, G. \& Ryan, C. (2011). The role of Chinese students as tourists and hosts for overseas travel. Asia Pacific Journal of Tourism research, 16(4), 445-464.

Llewellyn-Smith, C., \& McCabe, V. S. (2008). What is the attraction for exchange students: The host destination or host university? Empirical evidence from a study of an Australian university. International Journal of Tourism Research, 10(6), 593-607.

Lockyer, T. \& Ryan, C. (2007). Visiting friends and relatives - Distinguishing between the two groups: The case of Hamilton, New Zealand. Tourism Recreation Research, 32(1), 59-68.

López, X.P., Fernández, M.F. \& Incera, A.C. (2016). The economic impact of international students in a regional economy from a tourism perspective. Tourism Economics, 22(1), 125-140.

Lue, C. C., Crompton, J. L., \& Fesenmaier, D. R. (1993). Conceptualization of multidestination pleasure trips. Annals of Tourism Research, 20(2), 289 301.

Marriott, J., Plessi, A.J. \& Pu, M. (2010). Export education: How do international students experience New Zealand's service to them. Interdisciplinary Journal of Contemporary Research in Business, 2(8), 29-41.

Min-En, A. T. (2006). Travel stimulated by international students in Australia. International Journal of Tourism Research, 8, 451-468.

Morrison, A.M. \& O'Leary, J. T. (1995).The VFR market: Desperately seeking respect. The Journal of Tourism Studies, 6(1), 2-5.

Moscardo, G., Pearce, P., Morrison, A., Green, D. \& O’Leary, J. (2000). Developing a typology for understanding visiting friends and relatives markets. Journal of Travel Research, 38, 251-259. 
Munoz, J., Griffin, T. \& Humbracht, M. (2017). Towards a new definition for "visiting friends and relatives". International Journal of Tourism Research, 2017, 1-9. Doi: http://dx.doi.org/10.1002/jtr.2110

Oppermann, M. (1993). Tourism space in the developing world. Annals of Tourism Research, 20, 535-556.

Pearce, P. L. (2012). The experience of visiting home and familiar places. Annals of Tourism Research, 39(2), 1024-1047.

Payne, K. A. (2010). Domestic travel by international students in New Zealand. PhD thesis, Southern Cross University, Lismore, NSW.

Ross, G. (1994) The Psychology of Tourism. Melbourne: Hospitality Press.

Ryan, C. \& Zhang, Z. (2007). Chinese students: Holiday behaviours in New Zealand. Journal of Vacation Marketing, 13(2), 95-120.

Seaton, A.V. (1994). Are relatives friends? Reassessing the VFR category in segmenting tourism markets. In A.V. Seaton (Ed.), Tourism: The state of the art (pp.316-321). Chichester: John Wiley and Sons.

Seaton, A.V. \& Tagg, S. (1995). Disaggregating friends and relatives in VFR tourism research: The Northern Ireland evidence 1991-1993. Journal of Tourism Studies, 6(1), 6-18.

Seaton, T. \& Tie, C. (2015). Are relatives friends? Disaggregating VFR travel 1994-2014. In E., Backer \& B., King (Eds.), VFR travel research: International perspectives (pp.2845). Bristol: Channel View Publicaions.

Shanka, T. \& Taylor, R. (2003). International student graduation ceremonies: An opportunity for local tourism. Asia Pacific Journal of Tourism Research, 8(2), 13-22.

Shani, A. \& Uriely, N. (2012). VFR tourism: The host experience. Annals of Tourism Research, 39(1), 421-440.

Shani, A. (2013). The VFR experience: 'Home' away from home?. Current Issues in Tourism, 16(1), 1-15.

Sherlock, K. (2001). Revisiting the concept of hosts and guests. Tourist Studies, 1(3), 271195.

Shone, M. C., Simmons, D. G., \& Dalziel, P. (2016). Evolving roles for local government in tourism development: A political economy perspective. Journal of Sustainable Tourism, 24(12), 1674-1690. doi:10.1080/09669582.2016.1184672

Smith, V.L. (1989). Hosts and guests: The anthropology of tourism. Philadelphia: University of Pennsylvania Press.

Taylor, R., Shanka, T. \& Pope, J. (2004). Investigating the significance of VFR visits to international students. Journal of Marketing for Higher Education, 14(1), 61-77.

Tourism Industry Association New Zealand (2013). Tourism 2025: Growing value together. Retrieved from: http://www.tourism2025.org.nz/assets/Documents/Tourism-2025Summary.pdf

Uriely, N. (2010). Home and away in VFR tourism. Annals of Tourism Research, 37(3), 854857.

Varasteh, H., Marzuki, A. \& Rasoolimanesh, S.M. (2015). Factors affecting international students' travel behaviour. Journal of Vacation Marketing, 21(2), 131-149.

Wang, Y. \& Davidson, M.C.G. (2008). Chinese student travel market to Australia: An exploratory assessment of destination perceptions. International Journal of Hospitality \& Tourism Administration, 9(4), 405-426. 
Weaver, D. B. (2003). The contribution of international students to tourism beyond the core educational experience: Evidence from Australia. Tourism Review International, 7(2), 95-105.

Williams, A., \& Hall, M. (2002). Tourism, migration, circulation and mobility: The contingencies of times and place. In C. M. Hall\& A. Williams (Eds.), Tourism and migration: New relationships between production and consumption. Dordrecht: Kluwer Academic Publishers.

Yousuf, M. \& Backer, E. (2015). A content analysis of visiting friends and relatives (VFR) travel research. Journal of Hospitality and Tourism Management, 25, 1-10.

Yousuf, M. \& Backer, E. (2017). Hosting friends versus hosting relatives: Is blood thicker than water? International Journal of Tourism Research, 19(4), 435-446. 

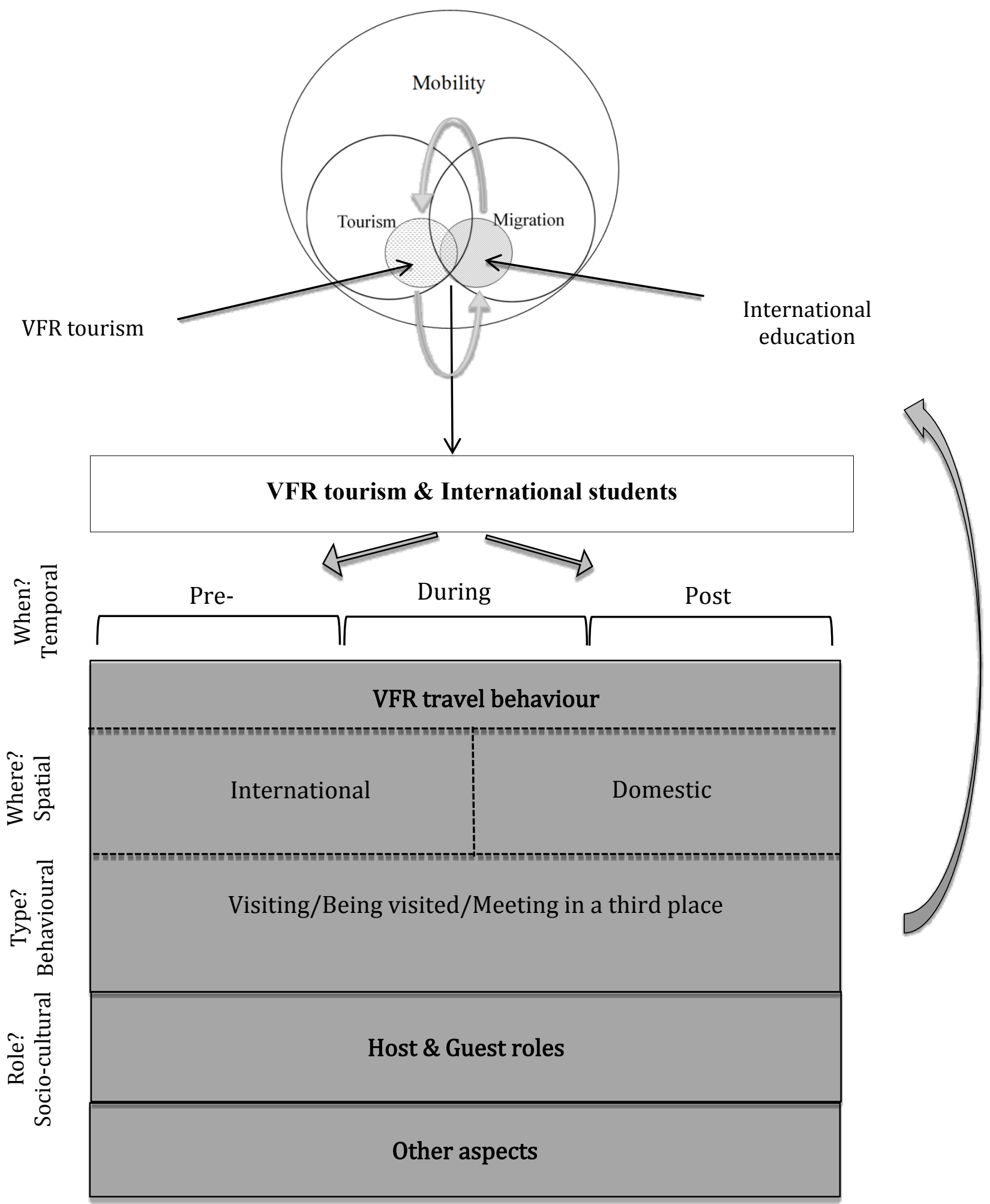